This is a slightly longer and revised version (v2.4) of a paper that appeared in Review of Philosophy and Psychology, (2014) 5:119-133.

\title{
How to Unify Theories of Sensory Pleasure: An Adverbialist Proposal
}

\author{
Murat Aydede \\ Department of Philosophy \\ University of British Columbia
}

\begin{abstract}
A lot of qualitatively very different sensations can be pleasant or unpleasant. The Felt-Quality Views that conceive of sensory affect as having an introspectively available common phenomenology or qualitative character face the "heterogeneity problem" of specifying what that qualitative common phenomenology is. In contrast, according to the Attitudinal Views, what is common to all pleasant or unpleasant sensations is that they are all "wanted" or "unwanted" in a certain sort of way. The commonality is explained not on the basis of phenomenology but by a common mental, usually some sort of conative, attitude toward the sensation. Here I criticize both views and offer an alternative framework that combines what is right in both while avoiding their unintuitive commitments. The result is the reductive (psychofunctionalist) adverbial sensory modification view of pleasure and displeasure.
\end{abstract}

I like tasting slightly chilled ripe strawberries on a hot summer day. I like the smell of a warm Ciabatta loaf just taken out of the oven. I like stroking the hair of my cat peacefully purring on my lap. I like hearing the laughter of my son. What, phenomenologically, unites these otherwise very different sensory episodes when I categorize them as pleasant? Similarly, I intensely dislike the sound and the feel of my fingernails scraping the chalkboard. I dislike the smell of rotten fish in my garbage. I dislike the taste of spoiled milk. I dislike pains. Again, what unites these qualitatively quite different sensory experiences when I find them unpleasant? A similar question naturally arises even within a single sensory modality such as pain when, for instance, we reflect on all the different kinds of sensory pain we can experience: qualitatively, a pinprick on my toe has almost nothing in common with the gnawing ache I feel in my abdomen when I overeat. Yet they are all painful (unpleasant). What makes them so? Insightfully answering these questions turns out to be difficult.

The enormous variety and diversity in the qualitative phenomenology of all pleasant experiences (as well as unpleasant ones) ${ }^{1}$ is striking, and many theorists have taken this to be a decisive reason to think that if some experiences are pleasant, they are so not because of their qualitative phenomenology. This is sometimes known as the "heterogeneity

\footnotetext{
${ }^{1}$ In what follows, I will mostly focus on pleasure and positive affect in general for convenience, but the discussion is applicable, mutatis mutandis, to negative affect (unpleasantness, including the painfulness of pains).
} 
problem" for any intuitively phenomenological conception of pleasure (and, generally, of positive and negative affect). ${ }^{2}$

Part of the problem here is the lack of a model on the basis of which we can understand the phenomenology of sensory episodes with positive or negative affect. Here I will sketch a model according to which affective phenomenology can be identified with a form of adverbial modification of sensory quality space. The model is adverbialist as far as affective phenomenology is concerned, but the metaphysics of affect is psychofunctionalist. To motivate the proposal, I first need to critically examine some traditional theories of pleasure and note their strengths and weaknesses. One of the interesting consequences of my proposal is that, if successful, it has the potential of unifying these apparently diverse theories that are thought to be in competition with each other.

\section{Sensory versus non-sensory affect}

First, some preliminaries. I want to concentrate on sensory pleasure (or displeasure), the kind of pleasure we feel when we are undergoing sensory experiences. But this, too, is ambiguous. I might find the very taste of a ripe strawberry very pleasant on a warm summer day when I am slightly thirsty and hungry. My pleasure attaches directly to how the strawberry tastes and doesn't go beyond it. In other words, I like the taste for what it is, or how it is in itself irrespective of what this taste may cause or indicate about the satisfaction of my other desires (i.e., the desires other than the intrinsic desire to taste the strawberry). In contrast, suppose I am a strawberry farmer, eagerly hoping to find my strawberries ready to be picked relatively early in the spring. I am not hungry or thirsty. I am in fact tired of eating strawberries. I bite the strawberry. I find the taste pleasant but this is mostly because the taste indicates that my strawberries are ready to be picked and sold - I am pleased that I will have a good return on the market. The former pleasure is sensory (for which I may often have an intrinsic desire - a desire for the taste sensation as an end in itself), the latter is not (I like the sensation because of what it indicates, not because of what it is in itself). So we can precisify the notion of sensory pleasure thus:

\footnotetext{
${ }^{2}$ Feldman (1997) and Carson (2000). The problem has been noted since ancient times and perhaps its most influential articulation is due to Sidgwick (1907):

Shall we then say that there is a measurable quality of feeling expressed by the word "pleasure," which is independent of its relation to volition, and strictly indefinable from its simplicity? - like the quality of feeling expressed by "sweet," of which also we are conscious in varying degrees of intensity. This seems to be the view of some writers: but, for my own part, when I reflect on the notion of pleasure - using the term in the comprehensive sense which I have adopted to include the most refined and subtle intellectual and emotional gratification, no less than the coarser and more refined sensual enjoyments - the only common quality that I can find in the feeling so designated seems to be that relation to desire and volition expressed by the general term "desirable," ... I propose therefore to define Pleasure - when we are considering its "strict value" for purposes of quantitative comparison - as a feeling which, when experienced by intelligent beings, is at least implicitly apprehended as desirable or — in cases of comparison — preferable. (1907/1981: 127)
} 
(SENSORY PLEASURE) A pleasure is sensory only if its subject experiences the pleasure solely due to undergoing some sensory qualities in a sensory experience.

As I intend to use the term, sensory qualities are phenomenal qualities of an experience (non-conceptually) registering or (re)presenting proper sensibles of a given sensory modality, or some combination thereof. Proper sensibles are the physical properties of the object of a sensory experience in a given sensory modality that can normally be properly sensed only in that modality. I intend to use 'sensory quality' a little more liberally to cover (possibly multimodal) collections of such qualities (e.g., experiencing flavors; both feeling and hearing one's nails scraping a chalkboard; feeling the kiss of your lover; hearing music). The distinction between sensory and nonsensory pleasures is probably not neat and clear-cut. But there are clear examples of both, and by stipulation in this paper, I mean to examine only the clear-cut examples of sensory pleasures. ${ }^{3}$

\section{Theories of sensory affect}

In the value theory literature, theories of sensory pleasure tend to fall into two broad categories. ${ }^{4}$ One group takes sensory pleasure to be a composite, composed of a complex of sensory qualities in a sensory experience — call this a sensation for short - and some sort of a mental (usually, conative) attitude to that sensation. Various proposals about the nature of the relevant attitude have been made, but most of them come down to some sort of desiring, wanting, preferring, or liking a sensation. Call such theories Attitudinal or Externalist Theories - externalist in that they take pleasantness to be external to the sensation, constituted by a conative or evaluative pro-attitude. ${ }^{5}$ A pleasant sensory experience (a sensory pleasure), then, consists of a sensation that is intrinsically desired or liked in a certain sort of way by the subject who is having the sensation. Here is a statement of what is probably the cleanest and most defensible version of this sort of theory developed by Chris Heathwood (2007: 32):

(DESIRE-THEORY)

a sensation $S$, occurring at time $t$, is a sensory pleasure at $t$ if, and only if, the subject of $S$ desires, intrinsically and $d e r e$, at $t$, of $S$, that it be occurring at $t$.

\footnotetext{
${ }^{3}$ Sometimes discussed in ethics literature under "the matters of mere taste." See Scanlon (1998), Parfit (2001), Sobel (2005).

${ }^{4}$ Here I will leave discussing the philosophy of mind literature on pain and pleasure to some other time. It is an interesting question why these two groups don't talk to each other.

${ }^{5}$ Here the list is long. Sidgwick (1907) may have started things going (see the quote above), but things are complicated - he used 'desirable' rather than 'desired.' See Alston (1968), Davis (1981, 1982), Brandt (1979), Feldman (1997, 2004), Heathwood (2007), among others, for defenses of attitudinal theories. Parfit (2011) and Brady (ms.) develop the attitudinal theory in terms of liking (or disliking) a sensation, where this hedonic attitude is taken to be different from desiring in that it's not responsive to reasons. I will return to this distinction later. Robinson (2006) gives an account of sensory pleasure that is hard to classify but seems closer to the attitudinal theories as he takes the pleasantness to essentially involve intentional and evaluative directedness toward sensations.
} 
The other group takes sensory pleasure to be a kind of feeling internal to the pleasant sensory experiences in that the pleasantness is an integral part of the very phenomenology of pleasant sensations and is not constituted by any conative or evaluative attitude. ${ }^{6}$ This group insists that sensory pleasure is, first and foremost, a phenomenological occurrence somehow identifiable across all pleasant sensations. Let's call these theories, Felt-Quality or Internalist Views, which can in turn be grouped into two subcategories: the views that take pleasure as either (i) a distinctive feeling, or (ii) a hedonic tone. Those who defend internalist theories have not always been very clear or even explicit about which version of the theory they intend to defend.

As far as I can tell, very few people hold the distinctive feeling view of pleasure. Early Moore (1903) is probably a good example: ${ }^{7}$

Suppose a man says I am pleased; and suppose it is not a lie or a mistake but the truth. Well, if it is true, what does that mean? It means that his mind, a certain definite mind, distinguished by certain definite marks from all others has at this moment a certain definite feeling called pleasure. Pleased means nothing but having pleasure, and though we may be more pleased or less pleased, and even, we may admit for the present, have one or another kind of pleasure; yet insofar as it is pleasure we have, whether there be more or less of it, and whether it be of one kind or another, what we have is one definite thing, absolutely indefinable, some one thing that is the same in all the various degrees and in all the various kinds of it that there may be. $(1903 / 1993: 12)$

But the hedonic tone views are popular. Here is Roger Crisp: ${ }^{8}$

If the advocate of heterogeneity is seeking in enjoyable experiences something like a special sensation, such as sweetness, or a tingle or feeling located in a certain part of the body, such as an itch or pins and needles, or indeed something like a perceptual quality such as redness, he will fail. But there is a way that enjoyable experiences feel: they feel enjoyable. That is, there is something that it is like to be experiencing enjoyment, in the same way that there is something that it is like to be having an experience of colour... Enjoyment, then, is best understood using the determinable-determinate distinction, and the mistake in the heterogeneity argument

\footnotetext{
${ }^{6}$ Sumner (1996) and Crisp ( 2006) use 'externalist' and 'internalist' to label the two categories of theories of pleasure. Carson (2000) and Heathwood (2007) use 'attitudinal' and 'felt-quality.' The names for the internalist subcategories are from Feldman (2001).

${ }^{7}$ See also, Brink (1989: p221): "the one and only intrinsic good is pleasure, which is understood as a simple, qualitative mental state." A more recent defense is Bramble (2011: p2): “... for an experience to be pleasant (or unpleasant) is just for it to involve or contain a distinctive kind of feeling, one we might call 'the feeling of pleasure itself', or simply 'the pleasant feeling' (or, in the case of unpleasant experiences, 'the unpleasant feeling')."

${ }^{8}$ See also, among others, Broad (1930), Duncker (1941), Sprigge (2000), Smuts (2011), Labukt (2012).
} 
is that it considers only determinates. Enjoyable experiences do differ from one another... But there is a certain common quality — feeling good — which any externalist account must ignore. (2006: 109)

Here is Shelly Kagan:

It is obvious that loudness or volume is not a kind of sound. And it seems plausible to insist that loudness is not a single kind of component of auditory experiences. Rather, volume is a dimension along which sounds can vary. It is an aspect of sounds, with regard to which they can be ranked. Recognition of the qualitative differences between the sounds of a symphony, rain falling, and a bird chirping, does nothing at all to call into question our ability to identify a single dimension volume - with regard to which these and other sounds can be ranked. Similarly, then, pleasure might well be a distinct dimension of mental states, with regard to which they can be ranked as well. Recognition of the qualitative differences between the experiences of hiking, listening to music, and reading philosophy, need not call into question our ability to identify a single dimension — pleasure - along which they vary in magnitude. Once we have a picture like this in mind, we might in fact be prepared to insist that there is a sense in which pleasure is an ingredient common to all pleasant experiences. For it seems to me that there is a sense in which a specific volume is indeed an ingredient of a given sound, along with a particular pitch, and so forth. (1992: 172)

What unites the felt-quality views against the attitudinal views is the insistence that the pleasantness of sensations has a phenomenological reality that has a detectable occurrence in our sensory experiences. Very roughly, the distinctive feeling views take this reality to be a phenomenologically uniform occurrence across all pleasant experiences, whereas the hedonic tone views allow for variations in the phenomenological character of this occurrence (more on this below).

Attitudinal theories and felt-quality views have always been developed as competitors and are understood to be incompatible with each other. I will question below whether this view is in fact correct. But for now let me briefly discuss the main arguments for and against each view. This will motivate the framework I will introduce later.

\subsection{Arguments for attitudinal theories and against felt-quality views}

There are several arguments for attitudinal theories and against felt-quality views. Here are the most salient ones:

(1) Introspection. Introspective evidence favors the thesis that what unites all pleasant sensations is their being liked or desired and not there being a discernable phenomenal feel or tone common to all pleasant sensations (no felt-quality). Given the extreme phenomenological variation among sensations (diversity of sensory 
phenomenology - compare experiences like tasting a strawberry and one's tense shoulders being massaged, for instance), the attitudinal theorists think that introspection favors their side on the phenomenology of sensory affect. For instance, Heathwood writes: “... the phenomenology just doesn't bear it out - there doesn't seem to be any one feeling (or even "hedonic tone") common to all occasions on which we experience pleasure or enjoyment" (2007: 26).

(2) Heterogeneity. Given (1), the heterogeneity problem is not a problem for attitudinal theories. On the contrary, if a version of externalism is true, the heterogeneity of pleasures is explained.

(3) Motivation. Pleasant sensations are intrinsically motivating in that they all by themselves provide motivating (albeit defeasible) reasons for their subjects. Furthermore, that they intrinsically motivate is not a contingent feature of pleasant sensations: all pleasant sensations necessarily motivate. This is a straightforward consequence of attitudinal theories. ${ }^{9}$ In contrast, on felt-quality views, it is a mystery how a mere phenomenal quality, all by itself, can motivate. On such views, there is at best a reliable but contingent connection between pleasantness and motivation.

(4) Opposite valences. Unpleasantness is opposite of pleasantness. Attitudinal theories explain this on the basis of opposite attitudes (e.g., liking versus disliking, or attraction versus aversion), or same attitudes but opposite content (e.g., desiring and desiring not). By contrast, if pleasantness is a phenomenal/sensory quality, it's hard to understand how it could have an opposite.

(5) Conceptual Reduction. Attitudinal theories are reductionist in that they claim that the nature of sensory pleasure is just a matter of having certain types of mental attitudes toward sensations. For instance, according to DESIRE-THEORY, pleasantness of a sensation just consists in its being desired in a certain way. ${ }^{10}$ In this regard, these theories are intellectually illuminating: they advance our understanding of what pleasure is. By

\footnotetext{
${ }^{9}$ According to those attitudinal theorists who are also "reason internalists" (or desire-theorists about normative reasons), pleasant sensations are also always intrinsically good: necessarily, they, all by themselves, provide justifying (normative — albeit defeasible) reasons for their subjects — although the matter is complicated by the fact that it is possible to be a reason externalist while advocating a desire theory of sensory pleasure.

${ }^{10}$ As far as I can tell, all attitudinal theorists writing from within the tradition of value theory and moral psychology are conceptual reductionists in that they consider their theories to be supported by constructive conceptual analysis (as in, e.g., the analysis of knowledge, causation, value, etc.) and/or ordinary empirical observation (i.e., empirical evidence available in armchair). See, for instance, Heathwood (2007) for an explicit statement to that effect. However, it's possible, or even desirable, to promote these theories as proposing an a posteriori metaphysical reduction — see below.
} 
contrast, on a felt-quality view, pleasantness is just the instantiation of a quality in a sensory experience: this doesn't shed any light into the nature of pleasure. ${ }^{11}$

\subsection{Arguments against attitudinal theories}

Despite this impressive supportive line-up, attitudinal theories have their own peculiar problems. I will mention only two that have been traditionally much discussed. I will then develop my own argument against them.

\subsubsection{Attitudinal theories and phenomenology}

Although attitudinal theorists claim that introspective evidence favors their side, the matter is controversial - to put it mildly. First, common sense treats sensory pleasure as a feltquality, or at least as a kind of feeling. But feelings are paradigmatic phenomenal episodes: they are conscious phenomenological occurrences. Second, most defenders of felt-quality views, in fact, claim introspective evidence as one of the major arguments for their own view. Indeed most hedonic tone views, in particular, have been developed with the heterogeneity problem in mind. Although there seems to be serious confusion on how exactly to interpret these theories, the intention has always been that the affective tone of an experience isn't like the phenomenology of sensory qualities (qualia, sensations), but they are to be understood rather like sensory qualities "affectively toned" — the intuition being that this affective tone is a higher-order property (or a dimension) of first-order sensory qualities of experiences (or, a property of their instantiation). Thus affect has been thought to have a peculiar phenomenology somehow piggybacking on the ground-level phenomenology of the sensory qualities. But hedonic tone is a phenomenological occurrence, and in this sense, a feeling. Below I'll defend this sort of view.

\subsubsection{Desire-theories of pleasure and the Euthyphro problem}

The second problem is well discussed in the literature and is sometimes labeled as the "Euthyphro problem." Taking DESIRE-THEORY as our representative of attitudinal theories, we can put the problem by asking a question: If a sensation is pleasant for a subject and the subject desires it (intrinsically, contemporaneously, de re, etc.), is the sensation pleasant because the subject desires it, or does the subject desire the sensation because it is pleasant? The desire-theorist is committed to an affirmative answer to the

\footnotetext{
${ }^{11}$ Although, by stipulation, not relevant to the present concern of this paper, we can add another important argument:

(6) Unification. Attitudinal theories can naturally be extended to cover all kinds of pleasure, not just sensory pleasure. Intellectual pleasures (involving aesthetic, moral, prudential, emotional, etc. pleasures), however affectively strong or weak they may be, can be analyzed as cognitive and conative attitudes towards propositions such as desiring, wanting, believing (etc.) that $P$, where ' $P$ ' are the relevant propositions. This can be expressed in terms of constructions such as ' $S$ is pleased that $P$ ' or ' $S$ is displeased that $P$ '. In short, attitudinal theories have a unified account of sensory and propositional pleasures, whereas felt-quality views cannot be plausibly extended in a similar way to all propositional pleasures. See particularly Feldman (1992, 1997, 2004) and Heathwood (2007) for this line of argument.
} 
former question. ${ }^{12}$ But this would make a fairly common pattern of intentional explanation circular: people desire to have certain experiences because they desire to have them (= are pleasant), or they desire to end their pains because they desire not to have them ( $=$ their pains are unpleasant, painful). But the problem is more than just circular explanations: pleasant and unpleasant experiences provide intrinsic (motivating and normative) reasons for desires. If experiences have affect because of our desires, then those affect-constituting desires are arbitrary and cannot provide reasons for why we intrinsically want to have or avoid certain sensations, and so, rationalizing or justifying explanations to that effect are "built on sand". ${ }^{13}$ This is a serious worry, and as we'll see, it arises partly because the operative notion of desire has a certain intentional structure whose tokening is by its very nature responsive to reasons. ${ }^{14}$

\subsubsection{Intentionality of the attitudes}

Another way of seeing how serious the worry is is to reflect on the notion of desire (or other pro-attitudes) involved in the analysis. Desire theorists offer their analysis as a conceptual reduction of sensory pleasure to desire. For this analysis to be successful, we must have a fairly independent grasp of the notion of a desire involved in the analysis. But it seems fair to insist that any notion of desire (more or less in its ordinary sense or senses) must preserve the sense of answerability to reason queries. Here the worry isn't just the unintelligibility of desiring something for no reason whatsoever in general. Although this might be problematic, the worry is more specific about whether affectively neutral sensations can be desired for no reason whatsoever in any ordinary sense of desire.

To buttress this intuition, note that any ordinary notion of desire must preserve its intentionality, its directedness towards things. But now consider the DESIRE-THEORY as formulated by Heathwood (2007). Wisely heeding various theoretical pressures, Heathwood stipulates that the affect-constituting desires be not only intrinsic and contemporaneous with sensations towards which they are directed, but also be intentionally directed toward them de re. Although problematic, let's grant that beliefs and desires can themselves be $d e$ re - as opposed to their ascriptions being de re. Skipping the many

\footnotetext{
${ }^{12}$ As readily acknowledged by Heathwood himself (2007: 38-40).

${ }^{13}$ Parfit (2001: 24-25):
}

According to [desire-based theorists], instrumental reasons get their force, not from some intrinsic reason, but from some intrinsic desire. And on such theories, as we have seen, we cannot have reasons to have such desires. So all reasons get their force from some desire that, on these theories, we have no reason to have. Our having such desires cannot itself, I am arguing, give us any reasons. If that is true, desire-based theories are built on sand.

For discussions airing similar complaints, see Smith (1994) and Dancy (2000) among others.

${ }^{14}$ For lack of space, I will leave aside the issue of how felt-quality views attempt to handle the problem of reason-giving force of pains and pleasures (see, however, the concluding thoughts below). See Goldstein (1980), Hall (1989), Rachels (2000), and Brady (ms.) for useful discussion. 
subtleties here, we may take this requirement, on the part of affect-making desires, to have some sort of reference-sustaining ongoing causal relation to sensations. But of course not any ongoing causal relation to sensations will do: it needs to sustain reference (aboutness, directedness). What does this mean? The subject of the sensation must already be capable of thinking of her sensations in the sense of being capable of singularly referring to them and predicating a feature to them — note that such a thought would, by the very nature of what it's about, be an introspective thought. In this context, to say of a desire about a sensation that it is de re is to say that the sensation is such that the desire makes the subject aware of it - in some direct fashion. If the affect-making desires are desires in any ordinary, mundane sense, this is the sort of thing that an ongoing causal relation must sustain in a de re desire. ${ }^{15}$ Intentionality, even when de re, doesn't come cheap.

This is quite an expensive machinery to turn a sensation into a pleasant one. It is simply not credible that in order for one to have pleasant sensations one needs to be able to introspect one's sensations. Many animals that we intuitively take to be capable of having affective sensory experiences, as well as young infants, don't have the capacity to think (have desires) about their own sensations. ${ }^{16}$ To require that these thoughts be de re doesn't help - in fact it complicates things more as we are just about to see. Even in our own case, it is implausible to think that whenever we have pleasant sensations we have de re desires about these sensations. But, if so, it's even more implausible to think that it is our desires about them (to the effect that they occur) that turn them into pleasant sensations. This seems like a reductio, if the notion of desire is intentional as assumed by any ordinary sense of this term that gives the desirer the ability to form thoughts about the object of her desires.

So far we have looked into what must be involved in the intentionality of de re desires about one's own sensations. This is a matter of referential aboutness. But affectmaking de re desires aren't just intentional in this sense (referentially directed toward a res); like any other desires, they are also representational in that they have a world-to-mind direction of fit. This requires that desires have a propositional content. This means that de re desires have a predicational function predicating features to whatever they are about or directed toward. So what is the "predicate position" in the content of an affect-making de

\footnotetext{
${ }^{15}$ Heathwood takes this direct fashion to be an acquaintance relation: a subject has a de re desire about her sensation only if the subject is acquainted with this sensation. In a naturalistic context, I take this to require at least an ongoing causal relation to the sensation. Note that mere acquaintance with one's sensation is not sufficient for one to form singular de re thoughts about this sensation.

${ }^{16}$ It is puzzling why Heathwood thinks that his desire-theory is compatible with animals experiencing pleasures and pains: "I see no good reason to deny that the animals we intuitively take to be capable of experiencing pleasure and pain are also the ones that have desires. We have no hesitation in attributing painful sensations to, say, rats, but we likewise have no hesitation in explaining why, say, this rat ran to the trap by appealing to his desire for the cheese" (2007: 32, fn. 17). But the rat's desire for the cheese is one thing, and his desire for his own taste sensation of the cheese another. Is it really true that we have no hesitation to attribute introspective desires to rats about their own sensations?
} 
$r e$ desire? Heathwood says: "the subject of [sensation] $S$ desires, intrinsically and de re, at $t$, of $S$, that it be occurring at $t$ " (my emphasis). It turns out that there is no predication! The affect-making de re desires are merely quantificational. The "content" amounts to "this exists' read de re. The "reference" is guaranteed by an actual on-going causal relation and there is no predication on the reference to provide a content to the desire. But how could this be? There are complicated issues about whether such contents exist, and if they do, what they might be. I won't discuss them here but point out some bizarre consequences of desires with such contents.

Note that these affect-making contemporaneous de re desires are occurrent intentional states just as the sensations they are about are. Their content is guaranteed to be true whenever they are tokened, just as the contents of assertoric utterances of 'this is here now' are. When we are talking about the pleasantness of a sensation, it is bizarre to conceive of it as being constituted by a contemporaneous de re desire whose content, whenever tokened, is guaranteed to be true. This gets the direction of fit wrong. If an intentional mental state type is such that whenever it is tokened its content is guaranteed to be true, then, intuitively, it's not a desire. Moreover, in the cases at hand, it's not at all clear how a subject who is having a pleasant sensation (i.e., having a contemporaneous de re desire about a sensation she is having that it exist) can fail to also have a contemporaneous de re belief with the same content ('this exists')? Furthermore, these desires, whenever they are tokened, are guaranteed to be satisfied at the time of their tokening. In the case of unpleasant sensations such as pains, the contemporaneous de re desires with content 'this doesn't exist' fare better. However, they are not just false, when tokened, but are guaranteed to be false and frustrated at the time of their tokening. On the face of it, this is pretty bizarre. In any ordinary sense, the usefulness, indeed in general, the function of desires qua intentional conative states depend on their contents, generally, not being guaranteed to be true and satisfied, or to be false and frustrated. So the problem may not so much be whether there are any such desires - although this is by no means clear. Even if there are, pretty clearly they are useless desires, and if they are desires at all, they are anathema to the very point of having desires in one's mental economy in the first place.

It's rather puzzling to see that a desire-theorist is willing to buy into a heavy-duty machinery provided by the intentional and logical structure of desires to explain what makes pleasant sensations pleasant only to see her give it away by trivializing their propositional content, thus making one wonder how such otherwise fairly useless desires could render affectively neutral sensations pleasant or unpleasant. My point so far is not that the desire theorist cannot provide a coherent notion of some sort of desire-like processing of a sensation. Rather it is that the notion provided will not enable a conceptual reduction. The gestured notion towards a desire-like process is too foreign to any ordinary notion of desire. (I will offer an alternative below.) No wonder, then, the implication that 
the affect-making desires cannot have non-arbitrary rationalizing and justifying reasons sounds bizarre.

\subsubsection{Liking-theories of pleasure}

Perhaps, desire isn't the right attitude for the attitudinal theorist after all. Maybe all that is need for the conceptual reduction to proceed is some sort of generic and fundamental notion of a pro-attitude. In a context responding to objections similar to the ones raised above, Heathwood writes:

For surely there is some pro-attitude that we can bear towards things we have (i.e., towards true propositions) as well as towards present and past states of affairs. We can favor, or be into, or give a mental thumbs up to, past and present states of affairs just as well as to possible future ones. And we can give a thumbs up towards things we have. An attitude is there to be named. The question is simply whether it is ever appropriate to use 'desire' or 'want' to express this attitude. (2007: 33)

I say it's not appropriate, Heathwood says it is. But let's not quibble about terminology. Let's drop using 'desire' or 'want' to express the pro-attitude proposed in the conceptual reduction. We need a notion that is less problematic for a successful conceptual reduction. What about the attitudes of liking or disliking that one might take toward a sensation? So consider: ${ }^{17}$

(LIKING-THEORY)

a subject's sensation is a (un)pleasant sensation if, and only if, the subject intrinsically (dis)likes the sensation while having it.

For this proposal to constitute progress, we need to have a fairly good and independent notion of what the attitude of liking a sensation is. Now there are two options: either liking a sensation is an intentional state of a subject about her sensation, or it is not. If the former, then the considerations I brought to bear above to what is involved in the intentionality (referential aboutness) of de re desires equally applies mutatis mutandis to the liking-theory. For instance, the theory requires that a subject is capable of having pleasant sensations only if the subject can think about (refer to) her own sensations. Besides, even if liking is an intentional attitude, it's not clear whether it's much different than a desire. ${ }^{18}$ Or else we don't know much about its nature. It's not obvious, for instance, it is a clearer notion than the notion of a pleasant sensation. Indeed, people seem to use the 'liking' locution just to mean that they are having a pleasant experience - for instance, I used this locution myself in the introductory section above to introduce the problem in the first place.

\footnotetext{
${ }^{17}$ For proposals of this sort, see Armstrong (1962), Pitcher (1970), Tye (1995), Hall (1989), Kahane (2009), Parfit (2011), Brady (ms.), among others. Only the latter two are explicit about their choice of 'like/dislike' over 'desire' as they think there are crucial differences between them about their reason responsiveness.

${ }^{18}$ See Sobel (2011) for arguments for thinking that likings are a species of desires.
} 
If, on the other hand, liking is not an intentional state of a subject about her sensation, no such introspective capacity is needed: liking one's own sensation is simply not a matter of one's having any thoughts about it of any kind. In this case, liking one's sensation is a state of one that involves that sensation, plus some further facts presumably about the causal effects of that sensation on other states of the subject and/or about the causal dispositions of the subject in virtue of having that sensation. But in the absence of a more specific analysis of this causal role related to pleasant sensations as states of subjects, the liking-theory does little more than just label this state of subjects distinctively involved in their having a pleasant sensation. Moreover, even if more specifics about this causal role are offered, there is no reason to think that these will be affirmable on the basis of conceptual analysis alone. The real problem with this pleasantness-as-causal-role proposal, however, is that it is completely obscure how it is supposed to help explain the heterogeneity of pleasant sensations in a way that avoids positing common phenomenology (of a hedonic tone variety) - except perhaps by fiat. Remember that this is a fundamental motivation for the attitudinal theorist.

The liking-theorist's proposal, when liking is taken as a non-intentional relation, comes down to identifying all pleasant sensations according to a distinctive sort of causal role they have in the mental economy of the subject having the sensations. The likingtheorist, to compete with a hedonic tone theorist, needs to say that the distinctive affectmaking causal role of pleasant sensations has no phenomenology over and above the ground-level phenomenology of these sensations, and yet a subject undergoing various sensations can directly detect (know) when her various sensations are pleasant. Attitudinal theorists are convinced that phenomenal irrealism is the truth about the affective qualities (pleasantness/unpleasantness) of sensations. And yet, given the identification of pleasantness with a distinctive causal processing that pleasant sensations are subjected to (however heterogeneous these sensations may otherwise be), the liking-theorist has no way of blocking the hedonic tone theorist's potential move that identifies this distinctive causal role with the phenomenologically real hedonic tone of pleasant sensations - except by fiat. But denying by fiat that this causal role has no phenomenology whatsoever would be unmotivated in this context. Given that the default position, as noted by many, must be that all pleasant sensations feel good and their feeling so is a matter of phenomenology, we should stick to phenomenological realism about affect if we could, and by their own standards, the liking-theorist has now a way of doing this in a very natural and plausible way. We can say the following: what all pleasant sensations have in common phenomenologically is that they all feel good, and their feeling good/pleasant is constituted by the distinctive causal role that these sensations play in the mental economy of the subject who finds these sensations pleasant - the heterogeneity of pleasant sensory experiences is explained on the basis of the heterogeneity of the sensations involved and the affective commonality is explained by their common causal role. The alleged difficulty of introspectively spotting a phenomenological quality common to all pleasant sensory 
experiences is due to a faulty model of what it is to have a common phenomenology. Below I will offer a better model that will make sense of sensory heterogeneity despite affective commonality favoring the hedonic tone theories while preserving the central insights of attitudinal theories.

\section{The psychofunctionalist metaphysics and the adverbial phenomenology of sensory affect}

Despite my criticisms of attitudinal theories above, the defenders of such theories are on to something. Some sort of a "desire-like" state is involved somewhere in a state of sensory pleasure. When we have a pleasant sensation - for instance, when eating our favorite ice cream in the right circumstances - there is some sort of a tug that we feel toward the taste, we feel some kind of pull that makes us "want to continue having the sensation". ${ }^{19}$ But the ordinary intuitive notion of desire isn't up to capturing this. We end up getting into trouble as we keep trying to capture it using ordinary vocabulary. As I hope it's become clear above, the notion these theorists is after is, intuitively, a functional role notion, ${ }^{20}$ only partially and superficially capturable in terms of ordinary conative notions. Let's introduce the term 'p-desire' to denote the state type with the psychofunctional role of processing incoming sensory information in whatever ways that realize the pleasantness of sensations. ${ }^{21}$ What would this involve? Answering this question isn't an armchair affair, but a quick look at affective neuroscience suggests that this role consists of a complex processing of incoming sensory information that, among other things, ${ }^{22}$

- sets interruptible motivational parameters (motivational biasing — "more-of-this" or "less-of-this" or "stop-this" incoming stimulus);

- prepares the effector or psychomotor systems of the organism, providing actionpreparedness (motor biasing);

- provides appraisals of the incoming sensory information for its significance for the organism and for its potential for enhancing its behavioral repertoire (epistemic biasing);

- influences action preferences on the basis of the sensory stimuli's informational content for future behavior through associative or cognitive learning, habituation, incentive sensitization, etc.;

- provides input to more centralized concept wielding cognitive systems.

\footnotetext{
${ }^{19}$ Brandt (1979: 38) gives this as a definition of sensory pleasure.

${ }^{20}$ Actually, a psychofunctional role notion — see below. See Block (1980) for the distinction between functionalism and psychofunctionalism.

${ }^{21}$ See Aydede (2000), where p-desiring was called 'desiring*'. For a similar treatment of pain affect, see Clark (2005). The framework to be presented below was, in outline form, part of a paper co-written with Matt Fulkerson that was presented in the Pacific APA meeting in San Francisco, 2013. We hope to continue collaborating on this topic.

${ }^{22}$ See Berridge (2004), Rolls (2005).
} 
We can think of p-desiring as a complex modification (filtering, enhancing, biasing, amplifying, etc.) of the incoming sensory information that will causally influence, in the above ways, the subject's motivational, cognitive, and behavioral priorities in such a way that makes some of this available for the subject's conscious thoughts and conative attitudes. This may result, when appropriate or needed, in the subject's judging that she likes the taste, that she finds the taste pleasant, or in the subject's making a mental note that the taste is comparable to her favorite ice cream parlor's flavors, that she should come back here often, or tell about it to her friends, etc. ${ }^{23}$

P-desiring is for now largely a placeholder for whatever the scientific research will eventually reveal about the nature of this psychofunctional role. The claim here is that the metaphysics of sensory affect consists in a certain kind of causal processing or modification of incoming sensory information. P-desiring incoming sensory information is mostly a subpersonal process revealed in consciousness as a pleasant or unpleasant sensation. But its functional nature is not altogether hidden at the personal level - this is what makes attitudinal theories prima facie plausible. The pleasantness of the taste of a ripe strawberry consists literally in my being motivationally (motorically, epistemically, etc.) biased toward that very taste, and toward the strawberry for that matter, in the very experiencing of that taste. This is how that taste (and the strawberry) is being presented to my consciousness.

\footnotetext{
${ }^{23}$ Here is an analogy. Consider how a large scale intelligence gathering operation might proceed for a government central security agency. It starts with access to information generators in the relevant channels such as internet activity, cell phone conversations, or drone surveillance. The ensuing processing will be interest relative carried out against a huge set of background concerns and knowledge. If the operation is large scale, its initial stages needs to be automatized to weed out irrelevant data before it reaches the higher decision making centres. So the processing needs to establish a set of hierarchically organized filters, relevancy criteria, and priority handling procedures early on. For instance, complex algorithms are needed to prune the vast amount of initial data to a manageable set on the basis of potential relevancy criteria. This pruning may include looking for key words, search phrases, patterns of words/phrase structures, intonations, volume, geographical and temporal sources of the data, their combinations and repeating patterns, etc. Throughout this multi-stage processing we can imagine certain data being dropped all the while some others being retained and marked for further processing. These may be routed to different computational centres for extracting further information for their significance and relevance as well as levels of potential threat. As the information processing progresses, the amount of data to be processed will diminish, but these later stages will require more intelligence as they are closer to decision making stages. This requires more information integration from various different sources including past data, communication and coordination with other agencies, etc., as well as activation of further data gathering resources focused on a range of potential targets. These later stages will also involve mobilization of potential action units, readying plans and securing required resources and capacities, planning the consequences of these action plans, comparing their results against a set of goals, and eventually somebody's pushing the button, say, to fire a Hellfire missile on a target. By the time the decision is made, most of the contingencies and readiness for various actions must have already been planned and secured. Many times all this processing and planning will result in no action, sometimes operations that are underway will be aborted - depending on what other priorities take precedence in light of further developing events here and there. It is useful to think of the style of affective information processing involved in p-desiring as similar to this agency's processing of information to mark the significance of the incoming information, to prioritize and establish action plans accordingly, coordinate their execution in light of developing events, and record the history of the operation and the ensuing results for future actions. This is information processing for potential action and learning — it's inherently motivational.
} 
The pleasantness, in this sense, is the "felt evaluation" of that taste. ${ }^{24}$ When this taste is presented to me as such, I can rationally grasp it as such (as "desirable"). That is to say, I can conceptually respond to my experience by having appropriate thoughts. ${ }^{25}$ Thus, the pleasure I experience $(\approx \mathrm{p}$-desiring incoming sensory information) provides me with both motivational and normative reasons to desire the taste and the strawberry - in the ordinary sense of 'desire'. So I agree with Goldstein (1980) that the intrinsic goodness of pleasures and the intrinsic badness of (painful) pains are graspable as such, and that is the way they rationalize and justify our actions and thinking.

The phenomenology of pleasant or unpleasant conscious experiences would then consist of having sensory qualities being affectively (adverbially) modified in a certain sort of way. Just as the subpersonal processing can be seen as a kind of adverbial modification of the incoming sensory information for affect, the phenomenology of pleasant sensations would consist of having sensory phenomenology being affectively/hedonically "toned" this toning being the affective adverbial modification of sensory qualities. Another helpful analogy here might be to think of dancing ( $\approx$ experience) different dances (tango, waltz, swing, etc. $\approx$ different sensory qualities, sensations) fast, moderately, or slowly ( $\approx$ affective modification of sensory qualities as pleasant, neutral, unpleasant, etc.).

If anything like this picture is correct, we can make better sense of the controversy surrounding the introspective evidence claimed in support of both attitudinal and feltquality theories. Introspection seems to favor both of the following claims:

- There are no affective qualia in the sense in which there are sensory qualia ( $\approx$ sensory qualities registering/representing sensible properties of objects).

- Affectively non-neutral sensory experiences have an occurrent (but adverbial/tonic) phenomenology essentially indexed to sensory qualities of experiences and thereby to whatever extra-mental objects and their sensible properties these sensory qualities present.

These explain why when we try to "isolate" a quality or a feeling peculiar to sensory pleasure, we always seem to end up with the sensory qualities themselves directing our attention to the external objects and their sensible properties they present. In fact, that's why we also attribute affective qualities (like pleasantness or unpleasantness) to the (physical) objects of experiences. ${ }^{26}$ Try to isolate the fastness of a fast waltz or a fast tango, you can't do it without paying close attention to the waltz or the tango itself. Nevertheless, the "fastness" or "slowness" common to the different token dances can be

\footnotetext{
${ }^{24}$ Terminology is borrowed from Helm (2002) - although I am not at all confident that Helm would agree with me about the way in which I put that expression in use here.

${ }^{25} \mathrm{I}$, of course, as a member of species with relevant mental capacities.

${ }^{26}$ See Aydede \& Fulkerson (2013) for extensive elaboration of this point in the context of representationalism about affect.
} 
discerned. In fact, some dance types can themselves be classified as fast or slow - these might perhaps correspond to relatively hard-wired affective responses to certain kinds of sensations (e.g., sweet tastes). Just the fastness or slowness of dances can be recognized across all different types of dances, the pleasantness or unpleasantness common to various otherwise quite different sensations is detectable, indeed introspectively available. The analogy with dancing is only just that, of course - an analogy, intended to help understand how we can conceive of hedonic tone as adverbial/affective modification of sensory qualities. But it shows that there is nothing mysterious about the peculiar phenomenology of sensory affect — or at least, there needn't be any.

Note that the sense in which I am advocating an adverbial theory of affect is different than the sense in which Gosling (1969) describes Rylean views of pleasure as adverbial (see also Sobel 2002). Ryle was a behaviorist, I am not. I am a reductive physicalist who takes phenomenology very seriously. ${ }^{27}$ For me, what is essential is the adverbial modification (processing) of incoming sensory information (sensory qualities), not the behaviorally capturable activities of the agent. Nevertheless, Ryle's intuitions were onto something: "his digging was his pleasure, and not a vehicle of his pleasure" (1949: 108); "The enjoyment of a walk is not a concomitant, e.g., an introspectable effect of the walking, such that there might be two histories, one the history of the walk, the other the history of its agreeableness to the walker" (1954: 138). This is not quite right, but one can see what intuitions Ryle was tapping into. My proposal is, in a certain sense, to internalize Ryle's behavioral adverbialism, making it a matter of how the sensory qualities with their different and heterogeneous phenomenology are instantiated in conscious experience. This is the affective dimension of experiences with a continuum ranging from positive, passing through neutral, to negative hedonic tone. Likewise, in my story, there are no two separate histories because there are no two separate phenomenological existences. The realization of one is the adverbial realization of the other.

\section{Conclusion}

I conclude that the psychofunctionalist/adverbialist view of sensory pleasure I have sketched in this paper can capture what is right in both the Attitudinal and Felt-Quality Views of pleasure while avoiding their unintuitive consequences. I reject the distinctive feeling views of sensory affect (pleasure, in particular). But I remain sympathetic to the hedonic tone version of the felt-quality views. The extant formulations of this version suffer from a lack of a model on the basis of which we can make sense of the occurrent affective phenomenology common to sensory pleasures without succumbing into a common felt quality (or, common sensation) view. I take it that my model makes better sense of how affective phenomenology strikes us in introspection. The essence of this

\footnotetext{
${ }^{27}$ I address the worries about the explanatory gap between conscious phenomenology and its physical/functional realizers in Aydede \& Güzeldere (2005).
} 
phenomenology is conative/functional as there is clearly a desire-like element involved in feeling pleasure and displeasure. But equally clearly we cannot capture this element in terms of our ordinary notions of conative attitudes. If we don't recognize this, the century old debate (within value theory) between feeling and attitude theorists is bound to continue with no resolution in sight. ${ }^{28}$

\section{References}

Armstrong, D. M. (1962). Bodily Sensations. London, Routledge and Kegan Paul

Alston, W. (1968). "Pleasure.” In P. Edwards (Ed.), The encyclopedia of philosophy. New York: Collier-Macmillan.

Aydede, M. (2000). "An Analysis of Pleasure Vis-à-Vis Pain," Philosophy and Phenomenological Research, 61(3), 537-570.

Aydede, M., \& M. Fulkerson (2013). “Affective Qualities," presentation at the Pacific APA meeting, 2013.

Aydede, M., \& Güzeldere, G. (2005). "Cognitive Architecture, Concepts, and Introspection: An Information-Theoretic Solution to the Problem of Phenomenal Consciousness," Noûs, 39(2): 197-255.

Berridge, K. (2004). "Motivation concepts in behavioral neuroscience," Physiology \& Behavior, 81(2): 179-209.

Block, N. (1980). "Troubles with functionalism.” In Readings in philosophy of psychology, $1,268-305$.

Brady, M. (ms.). "Pain and the Euthyphro Dilemma," draft, University of Glasgow, 2013.

Bramble, B. (2011). "The distinctive feeling theory of pleasure," Philosophical Studies, 162(2): 201-217.

Brandt, R. (1979). A Theory of the Good and the Right. Oxford: Clarendon Press.

Brink, D. (1989). Moral Realism and the Foundations of Ethics. Cambridge: Cambridge University Press.

Broad, C. D. (1930). Five Types of Ethical Theory. London: Routledge and Kegan Paul.

Carson, T. L. (2000). Value and the good life. Notre Dame: University of Notre Dame Press.

Clark, A. (2005). "Painfulness is Not a Quale.” In Pain, M. Aydede (ed.), Cambridge: MIT Press.

\footnotetext{
${ }^{28}$ I would like to thank David Bain, Michael Brady, Linda Davies, and Matthew Fulkerson for their helpful comments on an earlier version of this paper. I am also grateful to David Bain and Michael Brady for their kind invitation to participate in the conferences they organized for the Pain Project in Glasgow in June of 2012 and 2013 where parts of this paper were presented, and for their generous hospitality, as well as for providing me with the opportunity to contribute to the special issue of this Journal they are editing. Thanks also to my students in my seminar on affect for very stimulating feedback on parts of this paper.
} 
Crisp, R. (2006). Reasons and the Good. Oxford University Press.

Dancy, J. (2000). Practical Reality. Oxford University Press.

Davis, W. A. (1981). "Pleasure and happiness," Philosophical Studies, 39(3): 305-317.

Davis, W. A. (1982). “A Causal Theory of Enjoyment,” Mind, 91(362): 240-256.

Duncker, K. (1941). “On Pleasure, Emotion, and Striving,” Philosophy and Phenomenological Research, 1(4): 391-430.

Feldman, F. (1992). “Two Questions about Pleasure.” In Philosophical Analysis, edited by D. F. Austin, pp. 59-81.

Feldman, F. (1997). “On the Intrinsic Value of Pleasures,” Ethics, 107: 448-466.

Feldman, F. (2001). Hedonism. In L. C. Becker, \& C. B. Becker, (Eds.), The Encyclopedia of Ethics. New York: Routledge, pp. 662-669.

Feldman, F. (2004). Pleasure and the Good Life. New York: Oxford University Press.

Goldstein, I. (1980). "Why People Prefer Pleasure to Pain," Philosophy, 55(213): 349-362.

Gosling, J. C. B. (1969). Pleasure and Desire: The Case for Hedonism Reviewed. Clarendon Press, Oxford.

Hall, R. (1989). “Are Pains Necessarily Unpleasant?”, Philosophy and Phenomenological Research, 49(4): 643-659.

Heathwood, C. (2007). "The reduction of sensory pleasure to desire," Philosophical Studies, 133: 23-44.

Helm, B. (2002). "Felt evaluations: A theory of pleasure and pain," American Philosophical Quarterly, 39(1): 13-30.

Kahane, G. (2009). "Pain, Dislike and Experience," Utilitas, 21(03): 327-336.

Kagan, S. (1992). "The limits of well-being," Social Philosophy and Policy, 9: 169-189.

Labukt, I. (2012). "Hedonic Tone and the Heterogeneity of Pleasure," Utilitas, 24(02): $172-199$.

Moore, G. E. (1903/1993). Principia Ethica. In T. Baldwin (Ed.). Cambridge: Cambridge University Press.

Parfit, D. (2001). "Rationality and Reasons." In Exploring Practical Philosophy: From Action to Values, eds. D. Egonsson, B. Petersson, J. Josefsson, and T. RönnowRasmussen. Aldershot.

Parfit, D. (2011). On What Matters, Vol. 1, Oxford University Press.

Pitcher, G. (1970). "Pain Perception." Philosophical Review, 79(3): 368-393.

Rachels, S. (2000). "Is unpleasantness intrinsic to unpleasant experiences?" Philosophical Studies, 99: 187-210.

Robinson, W. S. (2006). “What Is it Like to Like?”, Philosophical Psychology, 19(6): 743765. 
Rolls, E. T. (2005). Emotion Explained. Oxford University Press.

Ryle, G. (1949). The Concept of Mind, Chicago: University of Chicago Press.

Ryle, G. (1954a). "Pleasure," Proceedings of the Aristotelian Society, Supp. 28: 135-146.

Scanlon, T. (1998). What We Owe to Each Other. Harvard University Press.

Sidgwick, H. (1907/1981). The Methods of Ethics. 7th edn. Macmillan.

Sobel, D. (2002). "Varieties of hedonism," Journal of Social Philosophy, 33(2), 240-256.

Sobel, D. (2005). "Pain for objectivists: The case of matters of mere taste," Ethical theory and moral practice, 8(4): 437-457.

Sobel, D. (2011). "Parfit's Case against Subjectivism." In Oxford Studies in Metaethics, volume 6, edited by Shafer-Landau, Oxford University Press.

Sprigge, T. L. S. (2000). "Is the esse of intrinsic value percipi?: pleasure, pain and value," Royal Institute of Philosophy Supp. Volume 47: 119-140.

Smith, M. (1994). The Moral Problem. Oxford University Press.

Smuts, A. (2011). "The feels good theory of pleasure," Philosophical Studies, 155(2): 241265.

Sumner, L. W. (1996). Welfare, Happiness, and Ethics. Oxford: Clarendon Press.

Tye, M. (1995). Ten Problems of Consciousness: A representational theory of the phenomenal mind. Cambridge: MIT 